\title{
Wave Trajectory Study on the Coast of Lhoknga, Aceh Besar, Indonesia: A Numerical Model Approach
}

\author{
Setiawan, . $^{1^{*}}$ and Irham, M. ${ }^{2}$
}

\begin{abstract}
A numerical model of wave trajectory using shoaling and refraction formula was proposed in the coastal waters of Lhoknga, Aceh Besar, Indonesia. The developed model used a two dimensional (2D) numerical methods for wave trajectory with the input of wave height and period; $0.62 \mathrm{~m}$ and 8 second for high tide and $0.47 \mathrm{~m}$ and 6 second for low tide. This model was tested on site during low tide and high tide conditions for verification. The purpose of this numerical study is to trace the distribution of wave trajectory because of shoaling, wave breaking, and wave refraction. The model determines the wave height and crest pattern of the ray wave trajectory. The simulation result shows the pattern of the wave propagation at Lhoknga beach moves from the northwest to the east and south of the coast. The model also informs that the maximum wave height during high tide condition is $1.72 \mathrm{~m}$ and $1.31 \mathrm{~m}$ during low tide condition. The result indicates that the coast of Lhoknga has moderate wave conditions caused by a gentle beach bathymetry slope.
\end{abstract}

Keywords: Numerical model; shoaling; wave distribution; refraction; trajectory.

\section{Introduction}

The coast of Lhoknga is located on the west coast of the tip of Sumatra Island, Indonesia, in Aceh Besar district of Aceh province (Figure 1). This coast is unique because of its geographical location between the two major currents, which are the Indian Ocean and the Malacca Strait current [1,2]. Beside the geographical factors of the sea, this beach is also strongly influenced by the topographic area around the coast [3]. The topography of the Eastern and Southeastern coast of Lhoknga is a mountainous region bordering the sea [2]. The Northern part is a valley and lowland basin, and in the West is the Indian Ocean. The factors mentioned above are features affecting the nature of the wave propagation [4] in the waters of Lhoknga waters.

The interaction of wave propagation with coastal topography and the profile of bathymetry of Lhoknga (Figure 2) has unique wave dynamic compared to other coastal areas in Aceh. The existence of shoaling is due to beach bathymetry profile toward the coastal area causing refraction and diffraction of wave distributions [5,6] and therefore causes the spread of energy through divergence because of the influence of forces acting on the topography of the coast $[7,8]$.

\footnotetext{
1,2 Faculty of Marine and Fisheries, Syiah Kuala University, Banda Aceh 23111, INDONESIA

* Corresponding author: irham@unsyiah.ac.id
}

Note: Discussion is expected before June, $1^{\text {st }} 2018$, and will be published in the "Civil Engineering Dimension", volume 20, number 2, September 2018.

Received 03 May 2017; revised 26 February 2018; accepted 08 March 2018
Hence, the study of wave propagation on the coast of Lhoknga needs to be focused on how the wave propagation and wave trajectory path in this area react to the aspects of coastal geography and the dynamics of hydro-oceanography $[9,10]$.

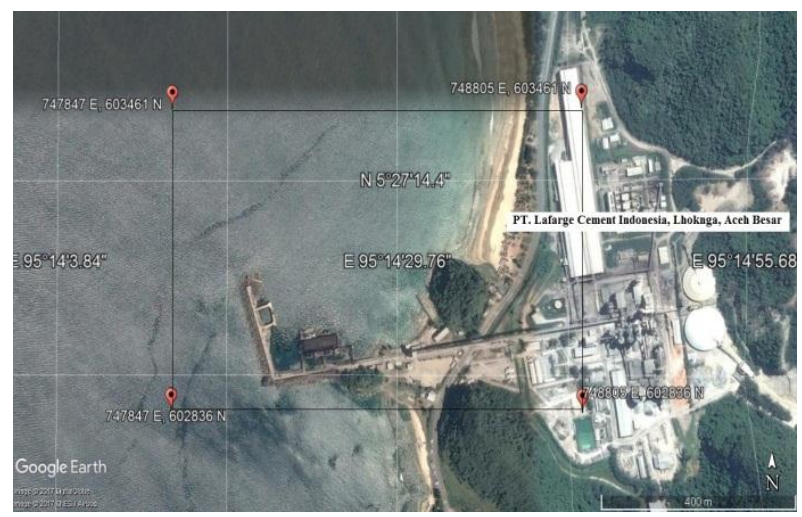

Figure 1. Map of Study Location of Lhoknga Coast, Aceh Besar, RGoogle Map (2017)

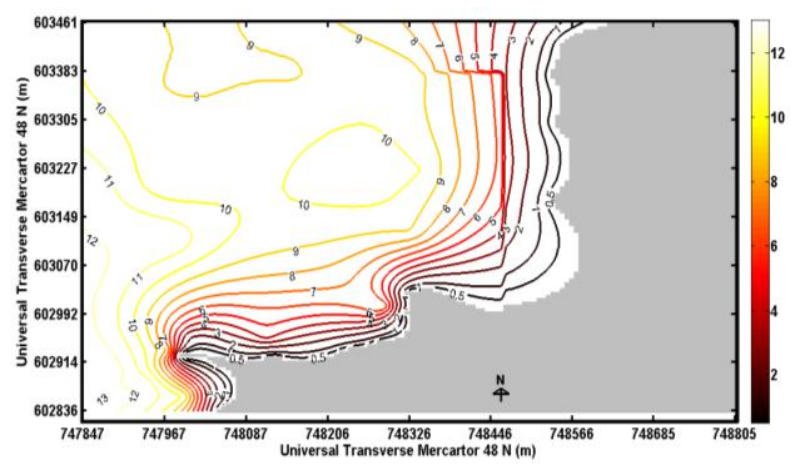

Figure 2. Bathymetry of the Coast of Lhoknga, Aceh Besar. 


\section{Shoaling}

Shoaling occurs because of the bathymetry effects that influence the wave trajectory characteristics toward shallow water near the beach. The assumption given to describe this shoaling is by defining that wave is constant throughout its propagation, so that the shoaling coefficient may mathematically be described as:

$\frac{H_{1}}{H_{0}}=K_{S}=\sqrt{\frac{n_{0} c_{0}}{n_{1} c_{1}}}=\sqrt{\frac{c_{0}}{2 n_{1} c_{1}}}$

$K_{s}$ can be simplified in the function of its depth, as follows

$K_{S}=\left[\frac{1}{\left(1+\frac{2 k d}{\sinh 2 k d}\right) \tanh k d}\right]^{\frac{1}{2}}=\left[\frac{\cosh k d}{(\sinh k d \cosh k d+k d)}\right]^{1 / 2}$

where:

$H_{1}$ and $H_{0}$ are wave height and initial wave height $n_{1}$ and $n_{0}$ are energy fraction and initial energy fraction

$c_{1}$ and $c_{0}$ are phase flow and initial phase flow

$K_{s}$ is shoaling coefficient

$k$ is wave number

$d$ is water depth

\section{Wave refraction}

Refraction is one of the factors causing the changes of the seafloor topography through the effects of erosion and deposition of coastal sediments [11,12]. Refraction plays a role in influencing energy through divergence on the headland, which affect the forces on offshore structures [13]. However, refraction also helps in describing on how rough the seafloor is, by looking at the phenomenon of the wave front $[14,15]$ (Figure 3).

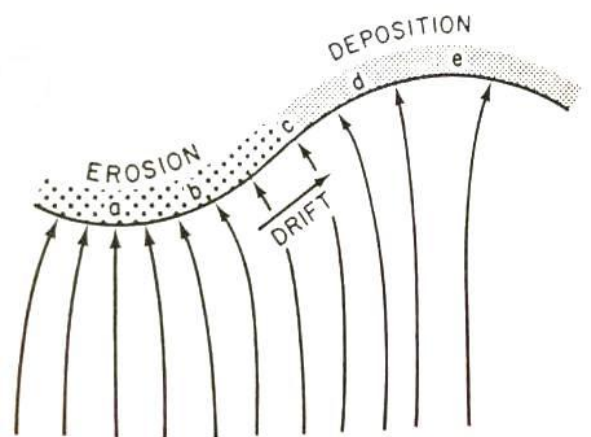

Figure 3. Wave Refraction Pattern toward the Coast [16]

The equation of the deflection coefficient used in this study is derived from the theory of wave trajectory equations, which can be graphically shown in Figure 4. To describe the evolution of a wave trajectory from the addition of a length along the path of $\mathrm{ds}$ or the addition of time where $d t=d s / c$, uses a kinematic principle defined as $[17,18]$ : $\frac{d \theta}{d s}=-\frac{1}{c} \frac{d c}{d n}$

In Equation (3) $\theta$ is the wave angle, $s$ is the distance, and $n$ is the energy fraction

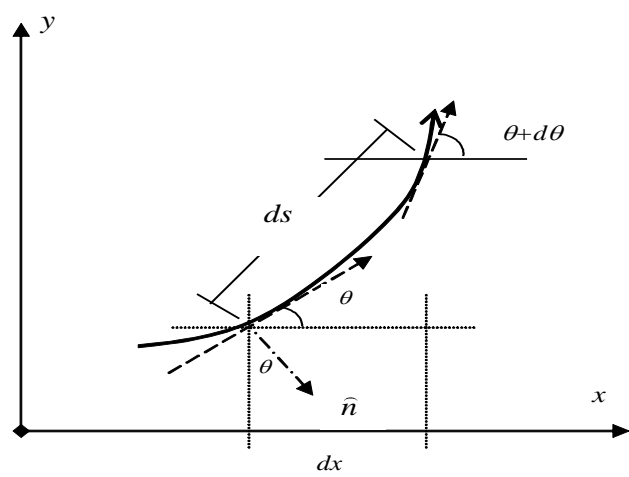

Figure 4. The Geometry of Wave Path Trajectory

Equation (3) denotes the change of angle along ds that depends on the rapid change of wave propagation in the normal direction, where the components are:

- Tangential direction (offensive direction)

$d x=\cos \theta d s$ and $d y=\sin \theta d s$

- Normal direction (perpendicular direction): $d x=\sin \theta d n$ and $d y=-\cos \theta d n$

Therefore Equation (3) can be reformulated into:

$\frac{d \theta}{d s}=\frac{1}{c}\left(\frac{\partial c}{\partial x} \sin \theta-\frac{\partial c}{\partial y} \cos \theta\right)$

From the velocity relationship, the change of distance, the change of angle, and the conservation of wave energy flux are formulated as the equations to calculate the refraction coefficient, ie:

$\frac{\partial^{2} \beta}{\partial t^{2}}+\frac{1}{2} p_{t} \frac{\partial \beta}{\partial t} q_{t} \beta=0$

where:

$p_{t}=-\frac{\partial c}{\partial x} \cos \theta+\frac{\partial c}{\partial y} \sin \theta$

$q_{t}=c\left(\frac{\partial^{2} c}{\partial x^{2}} \sin ^{2} \theta-\frac{\partial^{2} c}{\partial x \partial y} \sin 2 \theta+\frac{\partial^{2} c}{\partial y^{2}} \cos ^{2} \theta\right)$

Than the deflection coefficient $\left(K_{r}\right)$ can be defined as

$K_{r}=\sqrt{\frac{1}{\beta}}$.

Where, $d x$ and $d y$ are the distance fraction of $\mathrm{x}$ and $\mathrm{y}$ direction, $t$ is time, $\beta$ is the distance between the orthogonals, and $p_{t}$ and $q_{t}$ are wave power conservation coefficient

\section{Numerical Method}

The numerical method used in this study is based on equations of shoaling and wave refraction, which have been developed by Koutitas [17] and Ippen [18], while the input data provided as initial input for the numerical model is obtained from field measurements made during high tide and low tide [2]. 
The numerical solution of the wave equations in this study is solved by discretizing the wave equation (6) which also comprises the shoaling and refraction coefficients of (7), (8), and (9). By using this equation the wave height can also be calculated based on the wave equation below [19].

$H=H_{0} K_{s} K_{r}$

In which $H$ and $H_{0}$ are wave height and initial wave height respectively, $K_{s}$ is shoaling coefficient, and $K_{r}$ is refraction coefficient.

Using the central difference approach, the Equation of refraction coefficient (Equation (7)) can be obtained as:

$\beta^{n+1}=\frac{\left(p_{t} \Delta t-2\right) \beta^{n-1}+\left(4-2 q_{t} \Delta t^{2}\right) \beta^{n}}{\left(2+p_{t}\right)}$

with

$p_{t}=-\frac{\partial c^{n}}{\partial x} \cos \theta^{n}+\frac{\partial c^{n}}{\partial y} \sin \theta^{n}$

$q_{t}=c^{n}\left(\frac{\partial^{2} c^{n}}{\partial x^{2}} \sin ^{2} \theta^{n}-\frac{\partial^{2} c^{n}}{\partial x \partial y} \sin 2 \theta^{n}+\frac{\partial^{2} c^{n}}{\partial y^{2}} \cos ^{2} \theta^{n}\right)$

While the governing equation used in this numerical approach is the wave form Equation (6), namely:

$\theta^{n+1}-\theta^{n}=\frac{\Delta s}{c^{n}}\left(\sin \theta^{n} \frac{d c^{n}}{d x}-\cos \theta^{n} \frac{d c^{n}}{d y}\right)$

where:

$\frac{\partial c}{\partial x}=\frac{c_{i+1, j}-c_{i-1, j}}{\Delta x_{i}+\Delta x_{i+1}}$ and $\frac{\partial c}{\partial y}=\frac{c_{i, j+1}-c_{i, j-1}}{\Delta y_{i}+\Delta y_{i+1}}$

Here, the position of the new wave trajectory point is governed by the tangential component of the wave path equation in equation (4) which is discretized as:

$x^{n+1}=x^{n}+\Delta s \cdot \cos \left(\frac{\theta^{n+1}+\theta^{n}}{2}\right) d s$

$y^{n+1}=y^{n}+\Delta s \cdot \sin \left(\frac{\theta^{n+1}+\theta^{n}}{2}\right) d s$

where

$\Delta s=\Delta t \cdot c^{n}$

with point of $x^{n}, y^{n}, x^{n+1}$, and $y^{n+1}$ do not have to have a grid value.

To attain the distribution of the wave trajectory multiply (17) and (18) by interpolating the points in a grid (Figure 5). The interpolation formulation used is:

$$
\begin{aligned}
c^{n}= & c_{i, j}(\xi-1)(\eta-1)-c_{i+1, j}(\eta-1) \xi- \\
& c_{i+1, j+1} \xi \eta+c_{i, j+1} \eta(\xi-1)
\end{aligned}
$$

Where $x^{n}, y^{n}, x^{n+1}$, and $y^{n+1}$ are the positions of $x$ and $y$ at $\mathrm{n}$ and $\mathrm{n}+1$ time step respectively, $\beta^{n-1}, \beta^{n}$ and $\beta^{n+1}$ are orthogonal coefficients at $\beta$ at $n-1, n$, and $\mathrm{n}+1$ time step, $\theta^{n}$ and $\theta^{n+1}$ are wave angle at $\mathrm{n}$ and $\mathrm{n}+1$ time step, $i, i+1, i-1$ and $j, j+1, j-1$ are distance position on grid $x$ and $y$ at distance step, $\Delta x, \Delta y, \Delta t, \Delta s$ are the grid spaces of $x, y, t$ and $s$, and $\xi$ and $\eta$ are the elevation factor toward $\mathrm{x}$ and $\mathrm{y}$ grid.

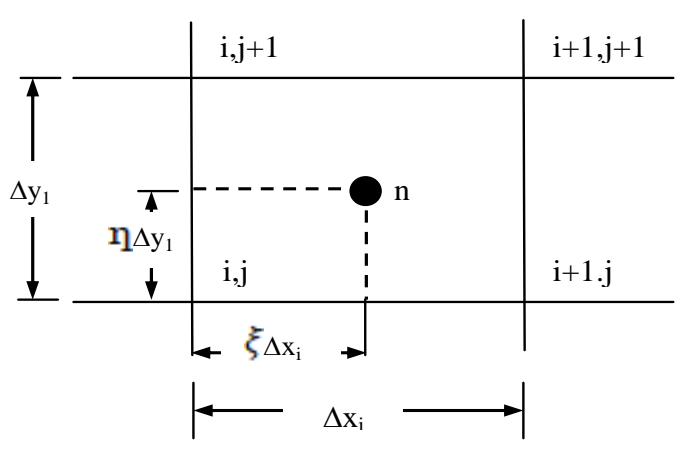

Figure 5. Four Points Interpolation used in Wave Refraction Model

\section{Results and Discussion}

The simulation result of wave trajectory path propagation in the coast of Lhoknga can be seen in Figures 6 and 7. These results show that the pattern of wave propagation at high and low tide is similar. This is caused by the angle of the incident wave at the initial condition both at low tide and high tide is equivalent, which is $240^{\circ}$ from the Northwest, based on the measurement result. In the pattern of trajectory wave radiation, the wave path does not show the generated distribution of wave height, but the result of the wave distribution is shown by the contour of shading which is overlaid with the spreading of wave trajectory.

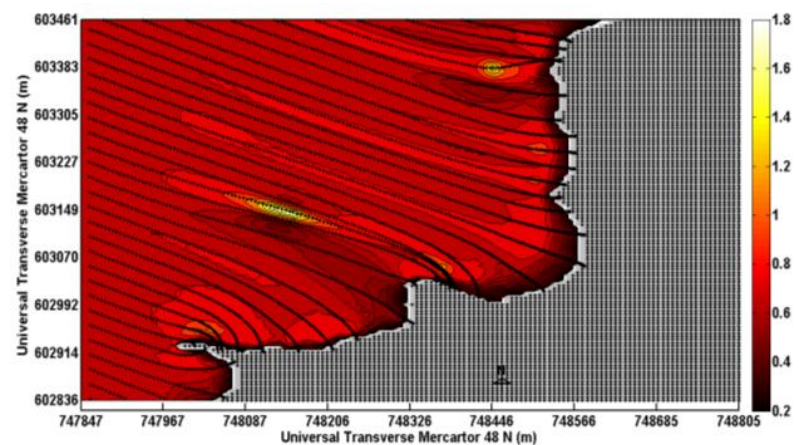

Figure 6. The Pattern of Wave Trajectory during High Tide Condition with the Initial Incoming Wave is $0.62 \mathrm{~m}$ and Wave Period is 8 Second.

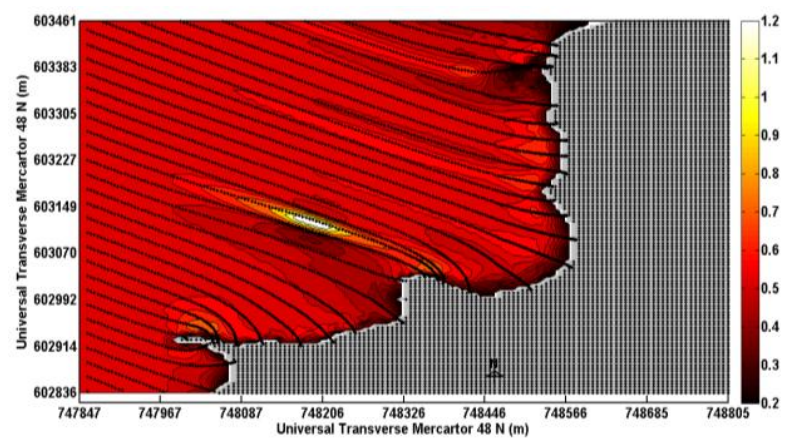

Figure 7. The Pattern of Wave Trajectory during Low Tide Condition with the Initial Incoming Wave is $0.47 \mathrm{~m}$ and Wave Period is 6 Second. 
The resulting wave distribution in Figures 6 and 7 show that the influence of the coastal bottom topography plays an important role in the distribution of wave dynamics. When viewed from the wave profile extracted from the parallel wave distribution at some point in this region (Figures 8 and 9), the maximum wave profile is visible as the wave will break leading to a shallow area near the shore that follows the rhythm of the beach bathymetry.

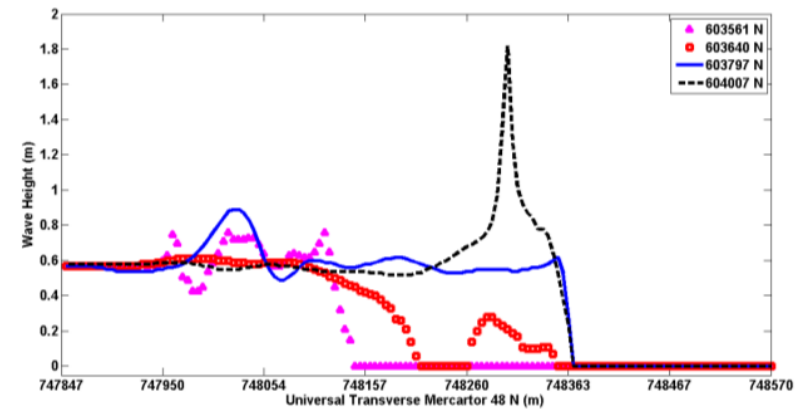

Figure 8. The Wave Profile of West-East at the Location of 603561 N, 603640 N, 603797 N, and 604007 N during High Tide Condition.

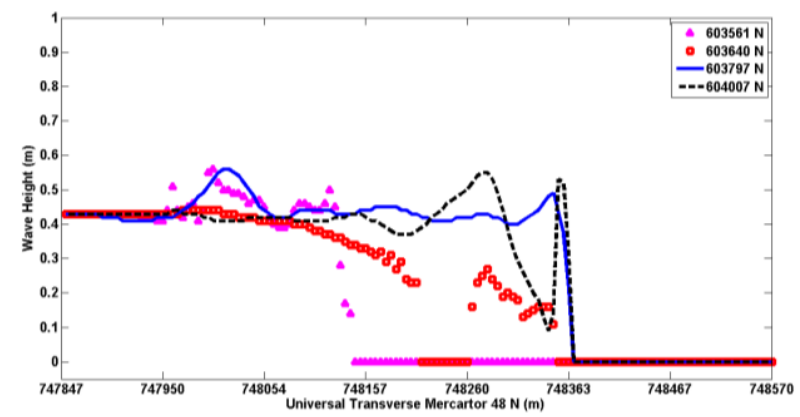

Figure 9. The Wave Profile of West-East at the Location of 603561 N, 603640 N, 603797 N, and 604007 N during Low Tide Condition.

The wave height profile also shows that when the waveform has reached maximum height (when the wave will break), the distribution of wave propagation also have a maximum energy value as well. According to Goncalves et al. [8], this state is characterized as the relationship of energy and amplitude in the propagation of waves, where high-energy waves can be characterized by the magnitude of the amplitude of the waves. On the other hand, low wave amplitude will result in low energy of wave propagation.

The simulation results of the wave field distribution model are shown in Figures 10 and 11. The model shows that the maximum wave height at high tide condition is $1.72 \mathrm{~m}$ and at low tide is $1.31 \mathrm{~m}$. Because of the high and low amplitude of the wave influenced by the topography of the sea-bed and the surrounding geographical profiles, it can be seen that the distribution of the wave field propagation generates a unique waveform and trajectory when it faces certain areas.

The wave height profile also shows that when the waveform has reached maximum height (when the wave will break), the distribution of wave propagation also have a maximum energy value as well. According to Goncalves et al. [8] this state is characterized as the relationship of energy and amplitude in the propagation of waves, where high-energy waves can be characterized by the magnitude of the amplitude of the waves. On the other hand, low wave amplitude will result low energy of wave propagation.

The results prove that the distribution of wave trajectory propagation in the cape region produces maximum wave heights whereas the bay area indicates the minimum wave height. Therefore, the propagation of wave trajectory path in this region causes divergence and convergence zones. The convergence zone occurs in the cape region that has a greater amount of energy than in the bay area (the divergence zone) (Figures 10 and 11). Zones that have large wave energy has a higher wave amplitude pattern that occurs in the divergence region while low wave amplitude distribution patterns occur in the convergence region.

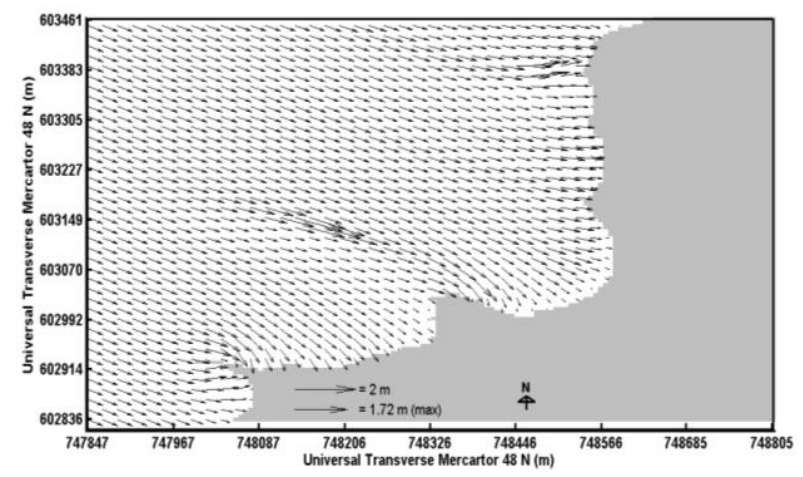

Figure10. The Distribution of Wave Field Pattern during High Tide Condition

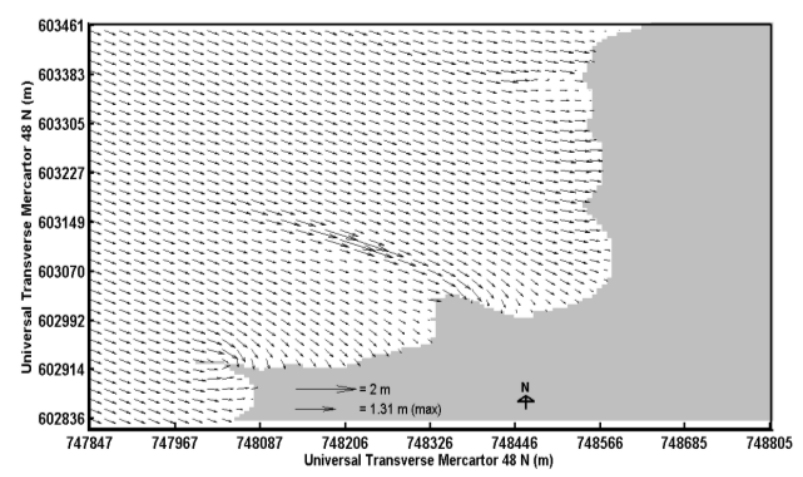

Figure 11. The Distribution of Wave Field Pattern during Low Tide Condition 


\section{Conclusion}

The numerical model result on this research shows that the profile and pattern of wave trajectory path and propagation both at high and low tide condition are similar because of the angle of the incident wave at initial condition is equivalent. However, the distribution of wave heights at high tide and low has significant differences as it is influenced by the variance in initial incoming waves and the topography at the study area. Furthermore, the propagation of wave trajectory path and wave distribution are influenced by zone of divergent (bay region) and convergent (cape region).

\section{References}

1. Rizal, S., Haridhi, H.A., Wilson, C.R., Hasan, A., and Setiawan, I., Community Collection of Ocean Current Data: An Example from Northern Aceh Province, Indonesia, SPC Traditional Marine Research Management and Knowledge Information Bulletin, 31, 2013, pp. 3-11.

2. Irham, M. and Setiawan, I., The Study of Flow Resulting from Wave on Lhonga Beach, Aceh Besar, Omni Akuatika, 13(1), 2017, pp. 5-12.

3. Anoop, T.R. and Kumar, V.S., Spatial and Temporal Variation of Surface-waves in Shallow Waters along the Eastern Arabian Sea, Ocean Engineering, 81, 2014, pp. 150-157.

4. Irham, M. and Setiawan, I., The Numerical Model of the Sediment Distribution Pattern at Lampulo National Fisheries Port, IOP Conference Series: Earth and Environment Science, 106 012067, 2018, pp. 1-6.

5. Jeschke, S. and Wojtan, C., Water Wave Animation via Wavefront Parameter Interpolation, ACM Transactions on Graphics, 34(3), 2015, Article 27:1-27:14.

6. Montblanc, T.F., Quinn, R., Izquierdo, A., and Bethencourt, M., Evolution of a Shallow Water Wave-dominated Shipwreck Site: Fougueux (1805), Gulf of Cadiz, Geoarcheology, 31(6), 2016, pp. 487-505.

7. Medina, G.G., Haller, H.T.O., and Rugiero, P., Wave Resource Assessment in Oregon and Southwest Washington, USA, Renewable Energy, 64, 2014, pp. 203-214.

8. Goncalves, M., Martinho, P., and Soares, C.G., Wave Energy Conditions in the Western French Coast, Renewable Energy, 62, 2014, pp. 155-163.
9. Setiawan, I., Ilhamsyah, Y., Miswar, E., and Haddrevi, A., A Prediction Study of Wave Propagation before and after Tsunami in Ulee Lheue Coastal Waters, Aceh, Indonesia, International Symposium Land Use after the Tsunami-Supporting Education, Research and Development in the Aceh Region, 2008, pp. 249254.

10. Irham, M., Fadla, Y., and Setiawan, I., The Spatial Distribution of Suspended Sediment Analysis along Krueng Cut River, Banda Aceh, IOP Conference Series: Earth and Environment Science, 106 012066, 2018, pp. 1-6.

11. Soomere, T. and Vika, M., Simulated Wavedriven Sediment Transport along the Eastern Coast of the Baltic Sea, Journal of Marine Systems, 129, 2014, pp. 96-105.

12. Barnard, P.L., Schoellhamer, D.H., Jaffe, B.E., and McKee, L.J., Sediment Transport in the San Francisco Bay Coastal System: An Overview, Marine Geology, 354, 2013, pp. 3-17.

13. Zurkinden, A.S., Ferri, F., Beatty, S., Kofoed, J.P., and Kramer, M.M., Non-linear Numerical Modeling and Experimental Testing of a Point Absorber Wave Energy Converter, Ocean Engineering, 78, 2014, pp. 11-21.

14. Gomes, E.R., Mulligan, R.P., Brodie, K.L., and McNinch, J.E., Bathymetric Control on the Spatial Distribution of Wave Breaking in the Surf Zone of a Natural Beach, Coastal Engineering, 116, 2016, pp. 180-194.

15. Westfield, P., Richter, K., Maas, H.G., and Weib, R., Analysis of the Effect of Wave Patterns on Refraction in Airborne Lidar Bathymetry, The International Archives of the Photogrammetry, Remote Sensing, and Spatial Information Sciences, Volume XLI-B1, XXIII ISPRS Congress, 2016. pp. 133-139.

16. Swift, D.J.P., Coastal Sedimentation, Chapter 14, In Stanley, D.J. and Swift, D.J.P., Marine Sediment Transport and Environmental Management, John Wiley \& Sons, New York, 1976.

17. Koutitas, C.G., Mathematical Models in Coastal Engineering, Pentech Press Limited, London, 1988.

18. Ippen, A.T., Estuary and Coastline Hydrodynamics, McGraw-Hill, New York, 1966.

19. Dean, R. and Dalrymple, R., Water Wave Mechanics for Engineers and Scientist, Prentice Hall Press, 1984. 